\title{
Cholesterol Net Transport, Esterification, and Transfer in Human Hyperlipidemic Plasma
}

\author{
Phoebe E. Fielding, Christopher J. Fielding, Richard J. Havel, \\ John P. KANE, and PEgGy TUN, Cardiovascular Research Institute \\ and Departments of Medicine, Pediatrics, and Physiology, University of \\ California, San Francisco, California 94143
}

\begin{abstract}
A B S T R A C T Cholesterol esterification, cholesteryl ester transfer between lipoproteins, and cholesterol transport between lipoproteins and cultured cells have been measured in the plasma of 22 patients with primary hyperlipidemia and 10 normolipidemic subjects. In hyperbetalipoproteinemia, increase in plasma low density lipoprotein levels was associated with a reduction of cholesteryl ester transfer rates, and with a reversal of the normal direction of sterol transport between fibroblasts and their plasma culture medium. Instead of net transport from cells to medium there was a net uptake of sterol from plasma by the cells, despite a level of plasma lecithin/cholesterol acyltransferase activity that was within the normal range. In dysbetalipoproteinemia, esterification rates were increased above normal levels, but cholesteryl ester transfer was reduced and the direction of sterol transport between the cells and plasma medium was reversed, as in the hyperbetalipoproteinemic group. In hypertriglyceridemia, those subjects with cardiovascular disease showed a metabolic pattern similar to the hyperbetalipoproteinemic group. The subjects in this group without symptoms of cardiovascular disease showed a normal direction of sterol transport, normal or raised rates of cholesteryl ester transfer between lipoproteins, and an increased rate of sterol esterification in plasma that decreased towards normal levels as plasma triglyceride levels decreased. Despite their quite distinct metabolic patterns there was no consistent difference between the two hypertriglyceridemic groups in triglyceride or cholesterol levels, very low density lipoprotein composition, or electrophoretic or isoelectric focussing patterns. All hypertriglyceridemic
\end{abstract}

Dr. P. Fielding is an Established Investigator of the American Heart Association. Address all correspondence to Dr. P. Fielding.

Received for publication 13 April 1982 and in revised form 22 November 1982. subjects with documented cardiovascular disease showed reversed cell-plasma sterol transport and all subjects without such disease showed a normal direction of cell-plasma sterol transport. The results of this study indicate major and reproducible abnormalities in plasma cholesterol metabolism in several groups of subjects with genetically distinct hyperlipidemias, who are at risk for atherosclerotic vascular disease. The possible predictive value of sterol metabolic measurements in the analysis of cardiovascular disease is discussed.

\section{INTRODUCTION}

In normal human plasma, net transport of cholesterol from cells, cholesterol esterification by the lecithin/cholesterol acyltransferase (LCAT) ${ }^{1}$ reaction, and the ability to transfer preformed cholesteryl esters to acceptor lipoproteins, influence the composition of plasma lipoproteins (1-3). In human hyperlipidemia, the composition and concentrations of plasma lipoproteins are modified in ways that have been defined by biochemical studies. For example, in familial hypercholesterolemia both the concentration and cholesteryl ester content of low density lipoprotein (LDL) is increased (4-5); in dysbetalipoproteinemia an increased concentration of intermediate density lipoproteins (IDL) of abnormal apoprotein composition has been demonstrated (6-7); and in hypertriglyceridemia the increased level of triglyceride in very low density lipoprotein (VLDL) is associated with changes in composition and concentration in LDL and high density lipoproteins (HDL) (8-11). However, the effects of altered lipoprotein composition on cholesterol metabolism in plasma have received much less atten-

\footnotetext{
${ }^{1}$ Abbreviations used in this paper: apo, apoprotein; DTNB, dithiobis (2-nitrobenzoic acid); LCAT, lecithin/cholesterol acyltransferase.
} 
tion. In normal human plasma, LCAT and cholesteryl ester transfer activities can be envisaged as a part of a well-regulated sequence of reactions by which free cholesterol of cellular origin is converted to ester form and transported to lipoprotein particles (12), LDL and VLDL mainly, from which it can be cleared by the liver (13-15). The potential significance of this pathway can be seen from the effects of accumulation of free cholesterol that occurs in the plasma in LCAT deficiency (16). It may also not be coincidental that it is especially the accumulation of the major acceptors of LCAT-derived cholesteryl esters in human hypercholesterolemia that appears to be strongly correlated with the development of atherosclerosis $(17,18)$. It was the purpose of this research to evaluate the activities of the steps in this pathway in patients with well-defined forms of primary hyperlipidemia.

\section{METHODS}

The subjects who took part in this study were 22 patients with primary hyperlipidemia, and 10 healthy subjects matched to give a similar distribution of age and sex (Table I). The patient group was chosen to include individuals with one of the following characteristics: isolated elevation of LDL cholesterol concentration, dysbetalipoproteinemia documented by apoprotein (apo) E phenotype and VLDL cholesterol/triglyceride ratio, or hypertriglyceridemia without increased VLDL cholesterol/triglyceride ratio. Nephrosis was absent, thyroid function was normal, and there was no evidence of an immunoglobulin disorder. Blood was obtained from a brachial vein of subjects fasted overnight, mixed with one-twentieth volume of $0.2 \mathrm{M}$ sodium citrate solution ( $\mathrm{pH} \mathrm{7.5)}$, and centrifuged at $3^{\circ} \mathrm{C}(1,500 \mathrm{~g}, 30 \mathrm{~min})$ to obtain plasma. The plasma was used immediately for the analytical procedures that are described in detail below.

Determination of cholesterol esterification rates. Plasma was diluted fivefold with ice-cold $\mathrm{NaCl}(0.15 \mathrm{M})$, brought to $0.01 \mathrm{M}$ with Tris-HCl buffer (pH 7.4), and to $1 \mathrm{mM}$ with disodium EDTA. Quintuplicate or sextuplicate $100-\mu \mathrm{l}$ samples were taken by micropipette (Clay-Adams [Accufill], Div of Becton, Dickenson \& Co., Parsippany, NJ) into $0.9 \mathrm{ml}$ of cold $0.15 \mathrm{M} \mathrm{NaCl}$, then $1.0 \mathrm{ml}$ of methanol and $1.0 \mathrm{ml}$ of chloroform were added. Portions of the chloroform phase were taken for fluorimetric analysis (using the Farrand 135800 spectrofluorimeter) of cholesterol and cholesteryl ester mass with cholesterol oxidase and esterase (19). The same number of samples was taken after $60 \mathrm{~min}$ of incubation at $37^{\circ} \mathrm{C}$. In some experiments, additional samples were taken at hourly intervals thereafter, for 2-3 h. The rate of esterification was determined as the rate of decrease in free sterol mass (2) from the linear portion of the plot (3). Such decrease was inhibited $95 \%$ by $1.5 \mathrm{mM}$ dithiobis(2-nitrobenzoic acid) (DTNB), an inhibitor of LCAT activity (20).

Determination of cholesteryl ester transfer rates to $V L D L$ and $L D L$. A major part of cholesteryl ester generated by the LCAT reaction in plasma is subsequently transferred by the activity of a specific transfer protein to VLDL and LDL (2-3). When LCAT is inhibited the rate of transfer is unchanged but in place of de novo synthesis, cholesteryl ester for transfer is derived from HDL (3). Cholesteryl ester transfer can therefore be assayed independently of LCAT activity as the rate of decrease in HDL cholesteryl ester in plasma where the LCAT activity has been inhibited by DTNB. As previously reported (3), for this purpose VLDL and LDL can be separated from HDL by precipitation with heparin and $\mathrm{MnCl}_{2}$ (21). After addition of Tris- $\mathrm{HCl}$ and EDTA as described above for the cholesterol esterification assay, DTNB was added to ice-cold plasma to a final concentration of $1.5 \mathrm{mM}$ and a portion $(1.5 \mathrm{ml})$ was then mixed with a one-tenth volume of heparin- $\mathrm{MnCl}_{2}$ solution (heparin $\left.10^{4} \mathrm{IU} / \mathrm{ml}-1.0 \mathrm{M} \mathrm{MnCl}_{2}\right)$. After centrifugation $(15,000 \mathrm{~g}$, 30 min at $3^{\circ} \mathrm{C}$ ), quintuplicate samples of supernatant solution were taken for analysis of cholesteryl ester. A similar analysis was made at intervals during incubation at $37^{\circ} \mathrm{C}$ as described for cholesterol esterification. The rate of decrease of supernatant cholesteryl ester, which was linear with time over the 60-min assay period, was then determined.

Determination of cholesterol net transport. The direction and velocity of transport was determined between cultured fibroblasts and plasma diluted in phosphate-buffered saline (PBS) (1). Human preputial skin fibroblasts were cultured in 6-cm Falcon dishes (Falcon Labware, Div. of Becton, Dickenson \& Co.). Cells were plated at an initial density of 6-8 $\times 10^{4}$ cells per dish and cultured in Dulbecco's modified Eagle's medium containing $10 \%$ fetal calf serum. When the dishes contained 8-10 $\mu \mathrm{g}$ of sterol (about three-quarters confluence) the cells were washed with human serum albumin $(4 \mathrm{mg} / \mathrm{ml}$ ) (pH 7.4) in PBS (four times), with buffer (four times), and then incubated with the same medium containing diluted plasma from which fibrinogen had been removed by immunoaffinity chromatography (1). Quintuplicate dishes of cells (and the same number of empty dishes) were filled with medium $(3 \mathrm{ml})$ containing $1.5 \%$ (vol/vol) plasma in buffer medium. These conditions were chosen because in normocholesterolemic plasma they represent that midpoint of cell sterol transport at which $\sim 50 \%$ of the cholesterol demand for esterification via the LCAT reaction is derived from the cells (1). Fibrinogen-depleted plasma was diluted as required on the basis of protein determination with the Folin phenol reagent (22). An initial 1-ml sample of medium was taken into methanol for analysis of free and esterified cholesterol mass (19). The remaining $2 \mathrm{ml}$ was incubated for $60 \mathrm{~min}$ at $37^{\circ} \mathrm{C}$. A second $1-\mathrm{ml}$ sample was taken for the same analysis. Quintuplicate dishes of cells that had been incubated with the plasma medium and the same number of unincubated dishes were washed as described above, and the cells were dissociated with $0.1 \mathrm{M} \mathrm{NaOH}$ and extracted with chloroform and methanol for analysis of free and esterified cholesterol. The rate of cholesteryl ester synthesis was unchanged by the presence or absence of cells, as previously described (1), and accordingly, the rate of transport of free cholesterol from cells to medium is represented by ([decrease in medium free sterol in the empty dishes] - [decrease in medium free sterol in the dishes containing fibroblasts]). By this definition, transport in the direction of cells to plasma medium has a positive sign, while net transport in the direction of medium to cells has a negative sign. In the same way, the transport of cholesteryl ester between cells and medium can be determined as ([increment of medium cholesteryl ester in the presence of cells] - [increment of medium cholesteryl ester in the absence of cells]). The significance of positive and negative signs is the same as for free sterol. In some experiments the fibroblasts were prelabeled with $\left[1,2-{ }^{3} \mathrm{H}\right]$ cholesterol (New England Nuclear, Boston, MA), which had been freshly repurified by thin-layer chromatography (23), and the rate of efflux was determined from cell cholesterol specific activity and the rate of appearance of radioactivity in unlabeled medium $(1,2)$. Quin- 
tuplicate initial and final samples were taken at a 60 -min interval, as described for the cholesterol mass measurements.

Lipoprotein analysis. Quantitative ultracentrifugal flotation was carried out by centrifugation of separate portions of serum in individual Beckman $\mathbf{4 0 . 3}$ rotor tubes (Beckman Instruments, Inc., Fullerton, CA) at medium densities of $1.006,1.019$, and $1.063 \mathrm{~g} / \mathrm{cm}^{3}(24)$. The concentration of total cholesterol, unesterified cholesterol, phospholipids, and triglycerides in the VLDL $(d<1.006 \mathrm{~g} / \mathrm{ml})$, intermediate density lipoprotein $(1.006<d<1.109 \mathrm{~g} / \mathrm{ml})$, LDL $(1.019$ $<d<1.063 \mathrm{~g} / \mathrm{ml})$, and HDL $(d>1.063 \mathrm{~g} / \mathrm{ml})$ fractions were calculated from the values for the infranatant and supernatant fractions. Total serum cholesterol and triglyceride levels were determined by an automated method (25). The percentage of cholesterol present as esters was determined enzymatically (19) and phospholipids were determined from measurements of lipid phosphorus (26). Electrophoresis of lipoprotein fractions in agarose gel was carried out by the method of Noble (27), as modified by Pagnan et al. (28). Isofocussing polyacrylamide gel electrophoresis of isoforms of apo $E$ in VLDL was carried out on lipoprotein samples delipidated with ethanol and ether as previously described (29).

Isolation of cholesteryl ester generating and acceptor fractions. VLDL and LDL acceptor lipoproteins were separated from plasma by precipitation with heparin and $\mathrm{Mn}^{++}$, as described above for transfer. The lipoprotein precipitate was washed with heparin- $\mathrm{Mn}^{++}$solution, then redissolved in $0.1 \mathrm{M} \mathrm{NaHCO}$, and heparin was removed by dialysis against $0.1 \mathrm{M} \mathrm{BaCl}_{2}$ (pH 7.0) (3). After removal of the insoluble barium heparinate by centrifugation, excess $\mathrm{Ba}^{++}$ was removed from the lipoprotein solution by dialysis against $0.15 \mathrm{M} \mathrm{NaCl}, 1 \mathrm{mM}$ disodium EDTA (pH 7.4). To obtain plasma free of VLDL and LDL acceptor lipoproteins, the plasma (2-4 $\mathrm{ml}$ from freshly drawn blood) was immediately passed through a column $(1 \times 20 \mathrm{~cm}$ of heparin covalently complexed with agarose (Sigma Chemical Co., St. Louis, MO) equilibrated with $0.15 \mathrm{M} \mathrm{NaCl}$. The nonadsorbed protein eluate (which contained no detectable apo B by immunoassay) was recombined with acceptor lipoproteins for studies of cholesteryl ester transfer as detailed below. In some experiments the adsorbed lipoprotein was recovered by passing $3 \mathrm{M} \mathrm{NaCl}(2 \mathrm{vol})$ through the column. The VLDL and LDL recovered in this way were pooled, dialyzed against $0.15 \mathrm{M} \mathrm{NaCl}-1 \mathrm{mM}$ EDTA (pH 7.4), and used in the recombination experiments as described above.

\section{RESULTS}

Characterization of patients. Some clinical features and characteristics of the lipoprotein abnormalities in the three groups of hyperlipidemic patients are summarized in Table $I$. The seven patients with hyperbetalipoproteinemia had predominantly increased LDL cholesterol. In addition, five of them had cholesterol-enriched VLDL, with total cholesterol/triglyceride ratios ranging from 0.50 to 1.43 , and the VLDL contained a distinct beta lipoprotein component. Four of these five patients and one of the two with ratios in the normal range fulfill criteria for the diagnosis of familial heterozygous hypercholesterolemia (30). The five patients with dysbetalipoproteinemia all had cholesterol-rich VLDL with a beta lipoprotein component and an apo E-2/2 phenotype. By contrast, none of the nine hypertriglyceridemic patients had cholesterol-rich VLDL; three of those with atherosclerotic disease had two electrophoretic components in their VLDL but none had a beta lipoprotein component. In each of the three groups some patients had documented atherosclerotic disease of coronary or peripheral arteries. Within groups, no differences in lipoprotein-lipid distribution or in lipoprotein-lipid composition distinguished those patients who had documented atherosclerotic disease. In particular, in the hypertriglyceridemic group, there were no significant differences in the unesterified cholesterol/phospholipid or cholesteryl ester/triglyceride ratios in VLDL.

Cholesterol esterification in hyperlipidemic plasma. The rate of cholesterol esterification in plasma was determined in terms of the rate of decrease in plasma free cholesterol mass during incubation at $37^{\circ} \mathrm{C}$. As shown in Fig. 1, rates in normocholesterolemic plasma were $17-52 \mu \mathrm{g}$ sterol esterified $\mathrm{ml}^{-1}$ plasma $\mathrm{h}^{-1}$. The mean rate was $32 \pm 10 \mu \mathrm{g}$ sterol esterified $\mathrm{ml}^{-1}$ plasma $\mathrm{h}^{-1}$, comparable with that reported in a previous study of plasma from persons fasted overnight (31). This rate was not significantly different from that found in the plasma of subjects with hyperbetalipoproteinemia $\left(24 \pm 7 \mu \mathrm{g}\right.$ sterol esterified $\mathrm{ml}^{-1}$ plasma $\left.\mathrm{h}^{-1}\right)$ (mean $\left.\pm \mathrm{SD}\right)$. As shown in earlier studies and confirmed here (Fig. 1), $>90 \%$ of LCAT activity in normocholesterolemic plasma was removed by immunoaffinity chromatography on immobilized antibody to apo D (1), indicating the presence of a structural complex in plasma between these proteins. Similar results were obtained with hyperbetalipoproteinemic plasma (Fig. 1); the rate of loss of free cholesterol from plasma was reduced by a mean of $89 \%$ as compared with a reduction of $90 \%$ in the normocholesterolemic group.

In dysbetalipoproteinemic plasma, rates of cholesterol esterification $\left(55 \pm 7 \mu \mathrm{g}\right.$ cholesterol esterified $\mathrm{ml}^{-1}$ plasma $\left.\mathrm{h}^{-1}\right)$ were significantly higher $(P<0.01)$ than in the control group (Fig. 1). Chromatography of this plasma through antibody to apo $D$ reduced this rate by a mean of $97 \%$, indicating the presence of a LCATapo $D$ complex in these patients as well. In the hypertriglyceridemic group two distinct patterns of LCAT activity were evident. In one subgroup esterification rates $\left(30 \pm 4 \mu \mathrm{g}\right.$ cholesterol esterified $\mathrm{ml}^{-1}$ plasma $\mathrm{h}^{-1}$ ) were within the normal range. All of these patients had documented vascular disease. In the other subgroup, esterification rates were $87 \pm 9 \mu \mathrm{g}$ cholesterol esterified $\mathrm{ml}^{-1}$ plasma $\mathrm{h}^{-1}$, significantly higher $(P<0.01)$ than the rate in any of the other groups. None of the patients in this group had evidence of vascular disease. However, in both groups of hypertriglyceridemic subjects, the major part of LCAT ac- 
TABLE I

Clinical and Lipoprotein Characterization of Hyperlipidemic and Normolipidemic Subjects

\begin{tabular}{|c|c|c|c|c|c|c|c|c|c|c|c|c|c|}
\hline \multirow[b]{2}{*}{$\begin{array}{l}\text { Sex/ } \\
\text { age }\end{array}$} & \multicolumn{2}{|c|}{$\begin{array}{c}\text { Initial serum } \\
\text { lipid levels }\end{array}$} & \multirow[b]{2}{*}{$\begin{array}{l}\text { VLDL- } \\
\text { TC }\end{array}$} & \multirow[b]{2}{*}{$\begin{array}{l}\text { IDL- } \\
\text { TC }\end{array}$} & \multirow[b]{2}{*}{$\begin{array}{l}\text { LDL- } \\
\text { TC }\end{array}$} & \multirow[b]{2}{*}{$\begin{array}{l}\text { HDL- } \\
\text { TC }\end{array}$} & \multirow[b]{2}{*}{$\begin{array}{l}\text { VLDL- } \\
\text { TC/TG }\end{array}$} & \multirow[b]{2}{*}{$\begin{array}{c}\text { VLDL } \\
\text { electrophoresis }\end{array}$} & \multirow{2}{*}{$\begin{array}{c}\text { Apo E } \\
\text { pheno- } \\
\text { type }\end{array}$} & \multirow{2}{*}{$\begin{array}{c}\text { Coronary } \\
\text { heart } \\
\text { disease }\end{array}$} & \multirow{2}{*}{$\begin{array}{c}\text { Peripheral } \\
\text { vascular } \\
\text { disease }\end{array}$} & \multirow[b]{2}{*}{ Diabetest } & \multirow[b]{2}{*}{ Lipid-lowering drugs } \\
\hline & TC & TG & & & & & & & & & & & \\
\hline
\end{tabular}

$m g / d l$

Hyperbetalipoproteinemia

\begin{tabular}{|c|c|c|c|c|c|c|c|c|c|c|c|c|c|c|}
\hline 1 & $M / 29$ & 298 & 61 & 3 & 3 & 228 & 33 & 0.25 & - & $\mathrm{E}-4 / 3$ & 0 & 0 & 0 & Colestipol \\
\hline 2 & $F / 70$ & 327 & 83 & 27 & 9 & 196 & 83 & 0.80 & Double pre- $\beta$ & E-3/3 & I & 0 & 0 & Premarin \\
\hline 3 & $\mathbf{F} / 34$ & 375 & 120 & 16 & 24 & 225 & 72 & 0.23 & Trace $\beta+$ pre $-\beta$ & E-4/4 & 0 & 0 & 0 & 0 \\
\hline 4 & $F / 41$ & 360 & 39 & 4 & 10 & 253 & 59 & 0.50 & $\beta+$ pre $-\beta$ & $\mathrm{E}-4 / 3$ & 0 & 0 & 0 & 0 \\
\hline 5 & $F / 52$ & 395 & 90 & 17 & 28 & 255 & 47 & 0.61 & $\beta+$ pre $-\beta$ & E-4/3 & $\mathbf{I}, \mathbf{Q}, \mathbf{A}$ & 0 & 0 & Colestipol \\
\hline 6 & $\mathrm{M} / 35$ & 460 & 77 & 40 & 80 & 270 & 30 & 1.43 & $\beta+$ pre $-\beta$ & $E-4 / 4$ & 0 & 0 & 0 & 0 \\
\hline 7 & $\mathrm{M} / 8$ & 343 & 62 & 30 & 6 & 258 & 36 & 0.94 & $\beta+$ pre $-\beta$ & E-3/3 & 0 & 0 & 0 & $\beta$-Sitosterol \\
\hline
\end{tabular}

Dysbetalipoproteinemia

\begin{tabular}{|c|c|c|c|c|c|c|c|c|c|c|c|c|c|}
\hline $8 \mathrm{M} / 45$ & 248 & 160 & 78 & 51 & 80 & 24 & 0.72 & $\beta+$ pre $-\beta$ & E-2/2 & 0 & $\mathbf{0}$ & $\mathbf{0}$ & 0 \\
\hline $9 \quad F / 59$ & 415 & 675 & 315 & - & $63^{\circ}$ & 21 & 0.57 & $\beta+$ pre $-\beta$ & E-2/2 & $\mathbf{A}$ & A & + & Clofibrate \\
\hline $10 \mathrm{M} / 58$ & 610 & 675 & 418 & 71 & 51 & 22 & 0.60 & $\beta+$ pre $-\beta$ & E-2/2 & 0 & $\mathbf{P}$ & 0 & 0 \\
\hline 11 F/55 & 300 & 204 & 105 & 50 & 84 & 42 & 0.67 & $\beta+$ pre $-\beta$ & $\mathrm{E}-2 / 2$ & I, A & 0 & 0 & Clofibrate \\
\hline 12 F/77 & 515 & 450 & 288 & - & $150^{\circ}$ & 37 & 0.83 & $\beta+$ pre- $\beta$ & $\mathrm{E}-2 / 2$ & $\mathbf{E}$ & $A, P$ & 0 & 0 \\
\hline
\end{tabular}

Hypertriglyceridemia

\begin{tabular}{|c|c|c|c|c|c|c|c|c|c|c|c|c|c|}
\hline $13 M / 40$ & 345 & 345 & 94 & 23 & 171 & 36 & 0.30 & Double pre- $\beta$ & E-3/3 & $\mathbf{I}, \mathbf{A}$ & 0 & 0 & 0 \\
\hline $14 F / 55$ & 455 & 4,250 & 358 & 13 & 35 & 11 & 0.10 & Double pre- $\beta$ & $E-4 / 3$ & $\mathbf{A}$ & 0 & + & 0 \\
\hline $15 F / 61$ & 280 & 470 & 92 & 46 & 109 & 26 & 0.35 & Single pre- $\beta$ & E-4/3 & A & 0 & + & Clofibrate \\
\hline $16 F / 54$ & 383 & 678 & 175 & - & $158^{\circ}$ & 28 & 0.22 & Double pre- $\beta$ & $\mathrm{E}-3 / 3$ & $\mathbf{I}, \mathbf{A}$ & $\mathbf{A}$ & 0 & 0 \\
\hline $17 \mathrm{M} / 42$ & 361 & 850 & 148 & 6 & 114 & 24 & 0.22 & Single pre- $\beta$ & E-3/2 & $\mathbf{I}, \mathbf{A}$ & 0 & 0 & Niacin \\
\hline $18 \mathrm{M} / 57$ & 248 & 625 & 97 & - & $102^{\bullet}$ & 43 & 0.19 & Single pre- $\beta$ & $\mathrm{E}-4 / 3$ & $\mathbf{0}$ & 0 & + & 0 \\
\hline $19 \quad F / 40$ & 185 & 345 & 67 & 9 & 74 & 24 & 0.24 & Single pre- $\beta$ & E-3/3 & $\mathbf{0}$ & 0 & + & 0 \\
\hline $20 \mathrm{M} / 51$ & 237 & 475 & 107 & 10 & 79 & 21 & 0.26 & Single pre- $\beta$ & $E-3 / 3$ & 0 & 0 & 0 & 0 \\
\hline $21 \quad F / 51$ & 419 & 900 & 208 & - & $140^{\circ}$ & 42 & 0.30 & Single pre- $\beta$ & E-3/2 & $\mathbf{0}$ & 0 & + & Niacin + colestipol \\
\hline $22 M / 63$ & 300 & 780 & 152 & 16 & 110 & 22 & 0.23 & Single pre- $\beta$ & $E-4 / 3$ & $\mathbf{0}$ & 0 & + & Clofibrate \\
\hline
\end{tabular}

Normolipidemia

\begin{tabular}{|c|c|c|c|c|c|c|c|c|c|c|c|c|c|}
\hline $23 \quad M / 39$ & 169 & 40 & 10 & 4 & 90 & 70 & 0.56 & Single pre- $\beta$ & $E-4 / 3$ & - & - & - & - \\
\hline $24 \quad F / 39$ & 167 & 49 & 5 & 2 & 97 & 52 & 0.56 & Single pre- $\beta$ & E-3/3 & - & - & - & - \\
\hline $25 F / 70$ & 212 & 82 & 14 & 14 & 131 & 64 & 0.20 & Single pre- $\beta$ & E-3/3 & - & - & - & - \\
\hline $26 M / 32$ & 230 & 92 & 15 & 20 & 147 & 50 & 0.46 & $\beta+$ pre $-\beta$ & E-3/3 & - & - & - & - \\
\hline $27 \mathrm{M} / 32$ & 170 & 32 & 10 & 8 & 102 & 57 & 1.00 & Single pre- $\beta$ & E-3/3 & - & - & - & - \\
\hline $28 F / 42$ & 176 & 52 & 12 & 0 & 146 & 56 & 0.33 & Single pre- $\beta$ & E-4/4 & - & - & - & - \\
\hline $29 M / 52$ & 188 & 41 & 6 & 9 & 74 & 81 & 0.52 & Double pre- $\beta$ & E-3/3 & - & - & - & - \\
\hline $30 \quad F / 49$ & 170 & 44 & 10 & 5 & 69 & 81 & 0.91 & - & - & - & - & - & - \\
\hline $31 \mathrm{M} / 50$ & 194 & 98 & 10 & 17 & 58 & 62 & 0.22 & Double pre- $\beta$ & $E-4 / 3$ & - & - & - & - \\
\hline 32 F/29 & 153 & 70 & 10 & - & $80^{\circ}$ & 60 & 0.23 & Single pre- $\beta$ & E-3/3 & - & - & - & - \\
\hline
\end{tabular}

- Includes IDL-cholesterol.

† Fasting plasma glucose $>140 \mathrm{mg} / \mathrm{dl}$.

A, abnormal angiogram; Q, Q waves on electrocardiogram (ECG); I, documented myocardial infarction; E, positive stress test; P, peripheral vascular disease (two or more pulses reduced in legs, or abnormal femoral angiogram); 0, normal ECG and no symptoms suggestive of coronary or peripheral atherosclerotic disease; TC, total cholesterol; TG, triglyceride. 


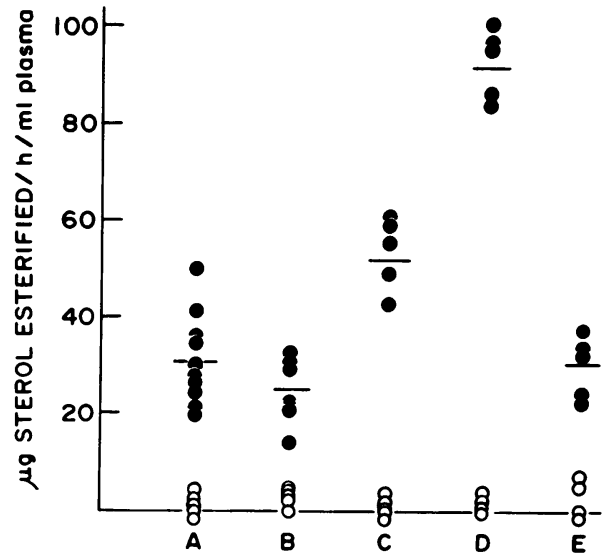

Figure 1 Esterification rates of cholesterol in plasma. Incubation was carried out at $37^{\circ} \mathrm{C}$ and the free sterol content of initial and incubated plasma was determined in quintuplicate as described in Methods. Simultaneous incubation was made of the same plasma samples from which apo D and associated apolipoproteins had been removed by immunoaffinity chromatography on immobilized antibody to apo $D$. Initial and final samples of medium in quintuplicate were assayed as for whole plasma. @, esterification rates in plasma; $O$, esterification rates in plasma-apo $D$. In all cases esterification rates are corrected to original plasma protein concentration. A, normolipidemic subjects; B, hyperbetalipoproteinemics; C, dysbetalipoproteinemics; D, hypertriglyceridemic subjects without documented vascular disease; $\mathrm{E}$, hypertriglyceridemics with documented vascular disease (see Table I).

tivity (98 and $96 \%$ in the first and second subgroups, respectively) was removed by immobilized antibody to apo $D$, indicating retention of the complex even when esterification rates in plasma were elevated. As all measurements of LCAT activity were in terms of the decrease of free cholesterol mass, these findings indicate that the LCAT bound to apo D in plasma is functional in esterification, in each of the normo- and hyperlipidemic groups.

In most of the hypertriglyceridemic patients (three of the first subgroup and five of the second) there were major $(>50 \%)$ changes in the level of plasma triglyceride in the course of the study. The rates of cholesterol esterification at the highest and lowest triglyceride levels were compared. The mean high and low triglyceride levels were $1,950 \pm 537$ and $446 \pm 366 \mathrm{mg} / \mathrm{dl}^{-1}$ in the subgroup with documented vascular disease and $1,570 \pm 807$ and $550 \pm 312 \mathrm{mg} / \mathrm{dl}^{-1}$ in the subgroup without evidence of such disease. In the first subgroup there was no significant change in the esterification rate assayed at high and low triglyceride levels $(33 \pm 1$ vs. $32 \pm 6 \mu \mathrm{g}$ cholesterol esterified $\mathrm{ml}^{-1}$ plasma $\mathrm{h}^{-1}$ ). In the second group, with high esterification rates at initial measurement, esterification rates at high and low triglyceride levels were $86.8 \pm 18.9$ and $58.3 \pm 22.3 \mu \mathrm{g}$ cholesterol esterified $\mathrm{ml}^{-1} \mathrm{~h}^{-1}$. Thus even at the lowest triglyceride level, esterification rates were significantly higher than in the normolipidemic group ( $P$ $<0.05$ ).

Cholesteryl ester transfer between lipoproteins in hyperlipidemic plasma. In normal plasma the major part of the cholesteryl ester synthesized by the LCAT reaction can be recovered in the VLDL and LDL fractions, which show the expected change in lipid composition during incubation in vitro (3). As shown in Fig. 2, in fasting normocholesterolemic plasma a considerable portion of ester synthesized by LCAT was recovered with VLDL and LDL. The fraction of ester synthesized that was transferred to VLDL and LDL $(0.6 \pm 0.1)$ was somewhat lower than the value $(0.8)$ found in a group of nonfasted normal subjects (3). A much lower fraction of synthesized cholesteryl ester was recovered in VLDL and LDL in the case of hyperbetalipoproteinemic plasma $(0.15 \pm 0.09) \quad(P$ $<0.01$ ), even though the level of LDL plus VLDL cholesterol was increased by an average of twofold (Table I). In the case of dysbetalipoproteinemic plasma, transfer was either negligible or was even reversed, so that in this case there was a net transfer of cholesteryl

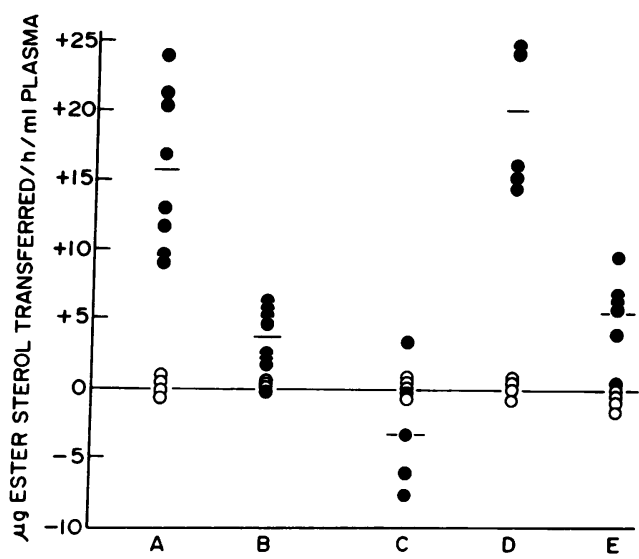

Figure 2 Cholesteryl ester transfer rates within plasma. Incubation of plasma, or plasma-apo $\mathrm{D}$, was carried out in the presence of $1.5 \mathrm{mM}$ DTNB and transfer was determined in terms of the loss of cholesteryl ester (determined enzymatically) from the soluble (HDL) fraction after precipitation of VLDL and LDL with heparin- $\mathrm{MnCl}_{2}$ (ref. 3). Quintuplicate initial and final samples were taken for analysis. 0 , cholesteryl ester transport rates in whole plasma; $\bigcirc$, cholesteryl ester transport rates in plasma-apo D. In all cases cholesteryl ester transport rates are corrected to original plasma protein concentrations. A, normolipidemic subjects; B, hyperbetalipoproteinemics; C, dysbetalipoproteinemics; D, hypertriglyceridemics without documented vascular disease; E, hypertriglyceridemics with documented vascular disease. 
ester mass during incubation out of VLDL and LDL into HDL. In the hypertriglyceridemic subjects, there was considerable variation in the rate of cholesteryl ester transfer. Nevertheless, the values obtained fell distinctly into two groups, and the subjects in these groups corresponded in each case to those with high rates of esterification and no apparent vascular disease, and those with normal rates of esterification and documented vascular disease. The fraction of ester synthesized by LCAT that was transferred to VLDL and LDL was $0.48 \pm 0.18$ in the first group, and $0.23 \pm 0.19$ in the second $(P<0.05)$. Because the rate of esterification in the first group was about threefold greater, the actual rate of transfer was on average about sixfold greater in the first than in the second group.

It has also been reported for normocholesterolemic subjects that transport of cholesteryl ester mass in plasma to VLDL and LDL was dependent upon the presence of apo D (1). As shown in Fig. 2, affinity chromatography on immobilized antibody to apo D in both normo- and hyperlipidemic patients of all groups removed essentially the whole of plasma cholesteryl ester transfer activity. Averaging the data from all measurements, $98 \pm 12 \%$ of transfer activity was removed in this way, confirming the presence in plasma of a functional association between apo $\mathrm{D}$ and cholesteryl ester mass transfer to VLDL and LDL.

To further investigate the basis of the inhibition of cholesteryl ester transfer in the affected patient groups, plasma from these subjects was incubated with VLDL and LDL isolated from the plasma of subjects with normal transfer, either without fractionation or after removal of autologous VLDL and LDL by heparinSepharose affinity chromatography (Fig. 3). As shown, cholesteryl ester transfer was significantly stimulated in dysbetalipoproteinemic plasma when the plasma was incubated with normal VLDL and LDL, and essentially normalized when endogeneous VLDL and LDL had been first removed. Similar results were obtained with representative plasma samples from patients with hyperbetalipoproteinemia, or with hypertriglyceridemia associated with reduced LCAT and transfer activities. On the other hand, the same reconstitution experiment in plasma from hypertriglyceridemics with normal transfer rates did not result in any augmentation of transfer. These results indicate that the block to transfer in hyperbetalipoproteinemic, dysbetalipoproteinemic, and certain hypertriglyceridemic subjects is the result not of a deficiency per se of the LCAT-transfer system, but of an inability of VLDL and LDL in the affected subjects to accept LCAT-derived cholesteryl ester. The greater transfer rate observed when endogeneous VLDL and LDL had first been removed from the plasma of the affected subjects by affinity chromatography, suggests that the

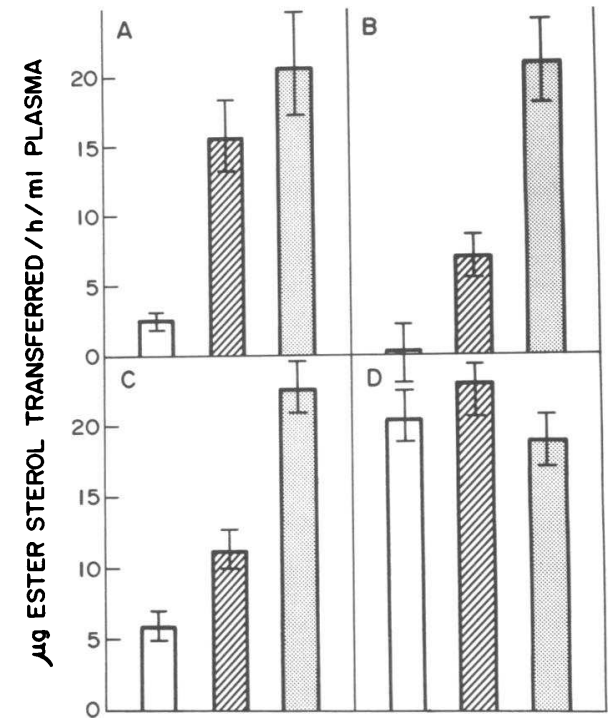

FigURE 3 Effects of acceptor lipoproteins (VLDL plus LDL) from plasma supporting normal cholesteryl ester transfer rates to plasma with normal and inhibited transfer. VLDL and LDL isolated with heparin and $\mathrm{MnCl}_{2}$ from hypertriglyceridemic plasma supporting normal transfer rates (subject 22$)(2.1 \mathrm{mg} / \mathrm{ml}$ protein) were added to an equal vol of whole plasma from subjects with hyperbetalipoproteinemia (subject 5, A), with dysbetalipoproteinemia (subject 10, B), with hyperglyceridemia associated with abnormal angiogram and inhibited cholesteryl ester transfer (subject 15, C), or to the patient's own plasma (D). Cholesteryl ester mass transfer rates so obtained (striped bars) were compared with rates in the same plasma samples diluted with $0.15 \mathrm{M} \mathrm{NaCl}$ in the place of the acceptor lipoprotein solution (open bars). Endogeneous VLDL and LDL were also removed from the plasma by heparin-agarose affinity chromatography (as described in Methods) to remove endogeneous acceptor lipoproteins, before the addition of acceptors from subject 22 under the conditions given above; cholesteryl ester mass transfer rates to the added VLDL and LDL were then determined (dotted bars). Values are mean $\pm S D$ of quintuplicate determinations.

abnormal VLDL and LDL inhibit the transfer of cholesteryl ester as well as being themselves ineffective acceptors. There was no difference in the extent to which cholesteryl ester transfer was stimulated in the same deficient plasma by the acceptor lipoproteins from normolipidemic plasma, or from the plasma of hypertriglyceridemic subjects with normal rates of cholesteryl ester transfer. There was also no difference in the stimulatory effect of VLDL and LDL, at the same concentration, isolated from plasma by heparin$\mathrm{MnCl}_{2}$ precipitation or by heparin-agarose affinity chromatography.

Cholesterol net transport between hyperlipidemic plasma and cultured cells. The direction and magnitude of cholesterol net transport between plasma and 
cultured fibroblasts was determined with normal and hyperlipidemic plasma from the subjects shown in Table I. As shown in Fig. 4, in the normal group, free cholesterol transport was in the direction of cells to medium, and its magnitude $\left(0.44 \pm 0.04 \mu \mathrm{g} \mathrm{h}^{-1}\right)$ was quite similar to that reported earlier for nonfasted plasma (1). This rate is higher than that previously reported $\left(0.26 \pm 0.03 \mu \mathrm{g} \mathrm{h}^{-1}\right)$, probably on the basis of the use in the present study of less confluent cells. In one normocholesterolemic subject, whose triglyceride and cholesterol levels were maintained in a range of $\pm 10 \%$ over a period of $12 \mathrm{mo}$, the net transport rate was $0.45 \pm 0.06 \mu \mathrm{g} \mathrm{h}^{-1}(n=6)$. Over the same period LCAT rates were $39.3 \pm 5.5 \mu \mathrm{g}$ cholesterol esterified $\mathrm{ml}^{-1}$ plasma $\mathrm{h}^{-1}$. There was a slight mean net uptake of cholesteryl esters from the medium to the cells $\left(0.09 \pm 0.04 \mu \mathrm{g} \mathrm{h}^{-1}\right.$ ) (Fig. 4). In all samples of hyperbetalipoproteinemic plasma there was a reversal of the normal direction of free cholesterol transport such that

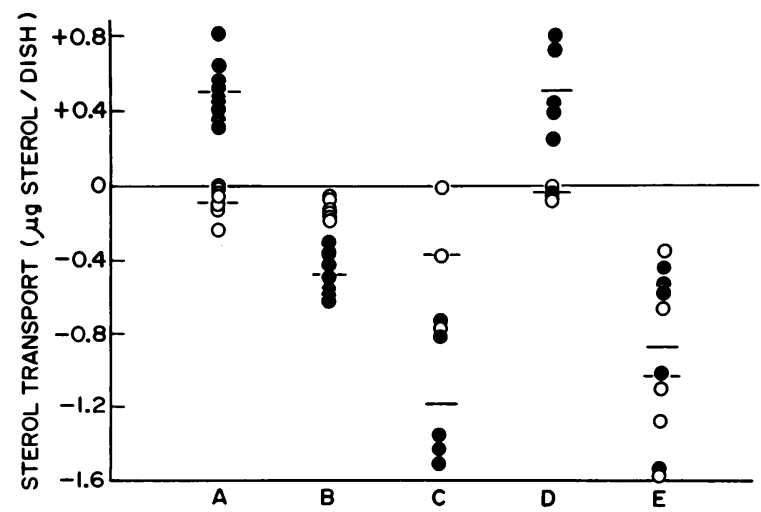

Figure 4 Cholesterol and cholesteryl ester net transport rates between cultured fibroblasts and plasma. Plasma at a dilution of $1.2 \% \mathrm{vol} / \mathrm{vol}$ (ref. l) was incubated in the presence or absence of cultured fibroblasts in 6-cm Falcon dishes; the dishes contained 6-8 $\mu \mathrm{g}$ cell sterol. $3 \mathrm{ml}$ of plasma medium diluted in PBS was added to the dishes; there was no loss of cholesterol by adsorption to empty dishes; quintuplicate dishes with and without cells were used for each data point. For each dish an initial 1-ml sample was taken for analysis of free and ester sterol content, and an equivalent sample was taken after incubation for $60 \mathrm{~min}$ at $37^{\circ} \mathrm{C}$. Rates of net transport of free and ester sterol were calculated from the differences in loss or gain of lipid in each fraction as detailed in Methods. $\bullet$, free sterol net transport between cultured cells and plasma medium; positive rates represent net transport in the direction of cells $\rightarrow$ medium and negative values indicate net transport medium $\rightarrow$ cells: $O$, esterified sterol net transport between cultured cells and plasma medium. The significance of positive and negative sign is the same as for free sterol. A, normolipidemic subjects; B, hyperbetalipoproteinemics; C, dysbetalipoproteinemics; $D$, hypertriglyceridemics without documented vascular disease; E, hypertriglyceridemics with documented vascular disease. cholesterol was taken from the medium to the cells (mean rate $-0.48 \pm 0.13 \mu \mathrm{g} \mathrm{h}^{-1}$ ). The rate of transport of cholesteryl esters was at the same rate and in the same direction as for normocholesterolemic plasma $\left(-0.11 \pm 0.04 \mu \mathrm{g} \mathrm{h}^{-1}\right)$. In dysbetalipoproteinemic plasma the direction of cholesterol transport was also reversed compared with normal plasma; the magnitude of the reversed transport was even greater on average, with a mean rate (medium $\rightarrow$ cells) of $-1.2 \pm 0.4 \mu \mathrm{g} \mathrm{h}^{-1}$. Transport of cholesteryl ester was moré variable but also in the direction of medium to cells $(-0.39 \pm 0.40$ $\mu \mathrm{g} \mathrm{h}^{-1}$ ) (Fig. 3).

In the plasma of the hypertriglyceridemic patients, two quite distinct and nonoverlapping patterns were again evident. Classification within the subgroups was identical to that found for LCAT and cholesteryl ester transfer activities. In the subjects with documented cardiovascular disease, the direction of net transport was reversed, as in the hyperbeta- and dysbetalipoproteinemic groups, and there was uptake (medium $\rightarrow$ cells) of both free and esterified cholesterol $\left(-0.98 \pm 0.48\right.$ and $-0.93 \pm 0.43 \mu \mathrm{g} \mathrm{h}^{-1}$, respectively). In the subjects without apparent cardiovascular disease, the direction of cholesterol net transport was normal (cells $\rightarrow$ medium) and its magnitude $(0.52 \pm 0.24)$ did not differ on the average from that of the normocholesterolemic group. In those subjects whose triglyceride levels changed ( $>50 \%$ ) over the study period, there was no apparent consistent change in the rate of cholesterol transport. At high and low triglyceride levels cholesterol net transport was $+0.48 \pm 0.21$ and $+0.55 \pm 0.12 \mu \mathrm{g} \mathrm{h}^{-1}$, respectively, in this group. Cholesteryl ester transport was $+0.00 \pm 0.11$ and $+0.01 \pm 0.08$ $\mu \mathrm{g} \mathrm{h}^{-1}$ under these conditions.

Balance studies were carried out to determine the content of cholesterol in cells and medium before and after incubation. In an experiment with hypertriglyceridemic plasma with reversed net cholesterol transport (Fig. 5), loss of free and esterified cholesterol from the medium was associated with the expected increase in total cholesterol in the washed cells. However, recovery of cholesteryl ester. was only one-half of that predicted and that of free cholesterol was correspondingly greater, suggesting that hydrolysis of some of the cholesteryl ester derived from plasma had occurred within the $60-\mathrm{min}$ incubation period. The intracellular metabolism of the interiorized cholesterol was further demonstrated by studies in which the incubation was continued for $5 \mathrm{~h}$. Under these conditions, however, the whole increment of free and ester cholesterol was recovered in the esterified form.

Similar results were obtained from balance studies with plasma samples representative of the other metabolic groups. In dysbetalipoproteinemic plasma (subject 10) a loss of $0.41 \mu \mathrm{g}$ total cholesterol from the 


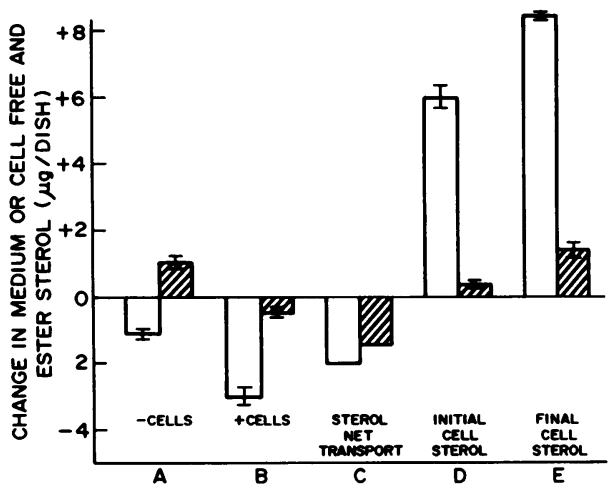

Figure 5 Cell and medium sterol balance in cell-medium net transport of free and esterified cholesterol. Initial and final medium free and ester sterol contents were determined as described in the legend of Fig. 4. Initial and final cell sterol contents were determined from quintuplicate plates exposed or not to plasma medium. Free sterol is shown by the open bars and ester cholesterol by the striped bars. The values represent from left to right: $A$, net increase and decrease in medium ester and free sterol during incubation for $60 \mathrm{~min}$ at $37^{\circ} \mathrm{C}$ in the absence of fibroblasts; $\mathrm{B}$, net change in medium free and ester sterol during incubation of the same medium in the presence of fibroblasts; $\mathrm{C}$, calculated change in cell sterol based on complete uptake of medium free and ester sterol during lipid transfer; D, initial cell free and ester sterol, determined on dishes of cells not incubated with plasma; E, final cell free and ester sterol of plates incubated with the plasma medium used in bars A and B. Values are mean \pm SD for quintuplicate dishes. Plasma was obtained from subject 16 .

medium was accompanied by an increase of $0.48 \mu \mathrm{g}$ of cholesterol in the washed cells after incubation. In a patient with hyperbetalipoproteinemia (subject 5) the corresponding mass changes were -0.78 and +0.62 $\mu \mathrm{g}$ cholesterol, and in subject 21 with hypertriglyceridemia associated with a normal direction of cholesterol net transport, medium and cell cholesterol mass changes under the same conditions were +0.51 and $-0.57 \mu \mathrm{g}$ cholesterol, respectively.

To determine whether such transport depended on the high affinity endocytosis pathway, mutant fibroblasts lacking the LDL receptor were used in incubation and balance studies, and the results compared with those obtained with normal fibroblasts incubated simultaneously under identical conditions. As shown in Fig. 6, there was no significant difference in the ability of normal and mutant fibroblasts to respond to plasma-derived cholesterol, indicating the independence of the processes described here from the LDL receptor mechanism. Similar experiments were carried out with plasma from hyperbetalipoproteinemic subjects in incubation with the receptor-deficient cells. Under conditions where cholesterol net transport was $-0.65 \mu \mathrm{g} \mathrm{h}^{-1}$ with normal cells (subject 5), the cor- responding cholesterol net transport with cells lacking the LDL receptor was $-0.55 \mu \mathrm{g} \mathrm{h}^{-1}$. The increments of cellular cholesterol mass measured in the same experiments were +0.45 and $+0.42 \mu \mathrm{g}$ sterol. These results confirm that cholesterol transport in these experiments is at least in large part independent of the LDL receptor pathway.

Cholesterol efflux from labeled cells to normo- and hyperlipidemic plasma. The differences described above related to cholesterol net transport, i.e., the difference between efflux and influx rates between cells and medium. The rate of cholesterol efflux to normoand hyperlipidemic plasma was determined with $\left[{ }^{3} \mathrm{H}\right]$ cholesterol-labeled fibroblasts under conditions identical to those used for determination of cholesterol net transport. There was no substantial difference in the ability of normo- and hyperlipidemic plasma to promote cholesterol efflux. Similar results were obtained from each of the different subject groups (Fig. 7). This finding indicates that the difference in the direction of cholesterol net transport between these subject groups must result in large part from differing rates of influx to cells from plasma. Because influx is equivalent to (efflux - net transport), this difference

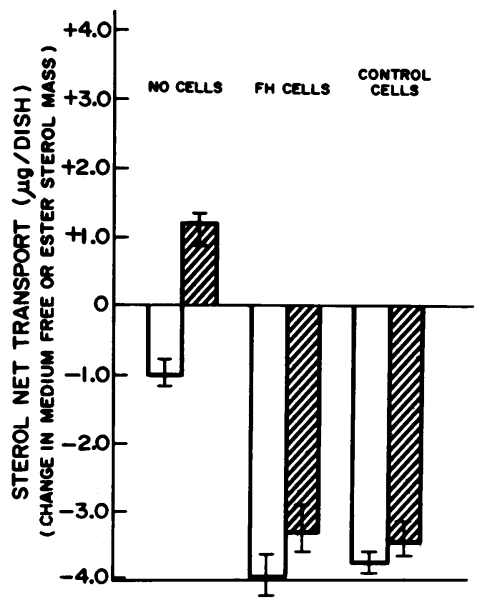

Figure 6 Cell and medium balance in cell-medium net transport of free and esterified cholesterol using normal and LDL-receptor-deficient cultured fibroblasts. The experiments were carried out as described in the legend in Fig. 5. Normal skin fibroblasts were as described in ref. 1. LDLreceptor-deficient fibroblasts (line GM 2000) were obtained from the Mutant Cell Repository, Camden, NJ. Free sterol is shown by the open bars and esterified sterol by the closed bars. The values represent from left to right: $A$, net increase and decrease in plasma medium free and ester cholesterol incubated in the absence of fibroblasts; $B$, the same experiment carried out in the presence of normal fibroblasts; C, the same experiment carried out in the presence of receptordeficient fibroblasts. The values given are for the means of quintuplicate dishes. Plasma was obtained from subject 14 . 


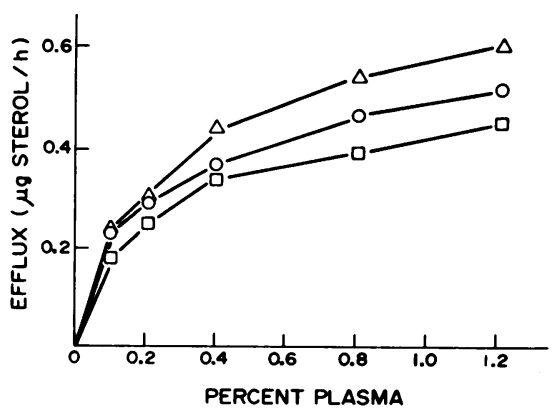

Figure 7 Sterol efflux as a function of medium plasma concentrations. Fibroblasts were prelabeled for $48 \mathrm{~h}$ with $\left[{ }^{3} \mathrm{H}\right]$ cholesterol to $8.1 \times 10^{4} \mathrm{dpm} / \mu \mathrm{g}$ sterol sp act. Initial and final $(60-\mathrm{min})$ samples were taken from duplicate dishes of cells at each experimental point, as radioactivity was determined with a Searle Mark II liquid scintillation system. The dishes contained $10.7 \mu \mathrm{g}$ sterol. $\Delta-\Delta$, hyperbetacholesterolemic plasma (subject 5); $\mathrm{O}-\mathrm{O}$, hypertriglyceridemic plasma (subject 15); $\square \longrightarrow \square$, normolipidemic plasma (subject 22). When LCAT was inhibited with $1.5 \mathrm{mM}$ DTNB, radioactivity was recovered exclusively as unesterified sterol.

between the two groups of hypertriglyceridemic subjects was marked: an average of $(0.54-[-0.98])$ or $1.52 \mu \mathrm{g} \mathrm{h}^{-1}$ in the group with documented heart disease and $(0.50-[+0.48])$ or $0.02 \mu \mathrm{g} \mathrm{h}^{-1}$ in the group without apparent disease, $\sim 75$-fold less. The corresponding calculated influx rates for normocholesterolemic, hyperbetalipoproteinemic, and dysbetalipoproteinemic subjects are $0.04,1.00$, and $1.70 \mu \mathrm{g} \mathrm{h}^{-1}$, respectively.

\section{DISCUSSION}

Present concepts of the regulation of the transport of cholesterol from cells to plasma have been largely drawn from experimental studies with normocholesterolemic plasma. From these studies the following linked steps have been proposed: net transport of cholesterol from cells to plasma dependent upon active cholesteryl ester synthesis by LCAT; the esterification of such cholesterol in a lipoprotein complex containing LCAT, apo A-I, and apo D, which catalyzes the removal of cholesteryl ester from the complex; and the accumulation of such esters in acceptor lipoproteins (particularly VLDL and LDL) whose capacity is finite (1-3). The second step has been earlier questioned by Albers et al. (32) from studies on two subjects. These authors concluded that only about one-half of LCAT is bound to apo $\mathrm{D}$. The present study corroborates our earlier research indicating that essentially all LCAT in plasma is present in a single structural and functional form. Albers et al. (32), in a study of cholesteryl ester exchange in one subject, with a radioisotope exchange assay, concluded that transfer of cholesteryl esters did not involve a complex containing LCAT. The results of the present study do not support this conclusion either, as in all groups affinity chromatography on anti-apo D removed both LCAT and cholesteryl ester transfer activity. Instead, the data presented here strongly support the concept that cholesterol transport, esterification, and transfer are closely linked functions. This conclusion is supported by Ihm et al. (33) who reported the copurification of LCAT and transfer activities from plasma.

It is a major finding of this research that these relationships are substantially modified in three groups of hyperlipidemic human subjects at risk for atherosclerosis (hyperbetalipoproteinemics, dysbetalipoproteinemics, and hypertriglyceridemics with documented vascular disease [Table II]). In all the three groups, the normal direction of cholesterol net transport was reversed. In other words, when cells were incubated with medium containing plasma from these subjects, the spontaneous direction of cholesterol transport was not from cells to medium, as in normal metabolism, but from medium to cells, so that the cells accumulated cholesterol in spite of normal or nearly normal levels of cholesterol esterification in the plasma. Efflux was also normal from cells to such medium. Accordingly, the abnormality lies in the accelerated influx of cholesterol from plasma to cells, which overwhelms the normal regulatory mechanism, represented by the coupled activities of apo A-I-mediated efflux, and LCAT-mediated esterification $(1,2)$.

The measurements reported in this study are of initial rates. With more prolonged incubation the ester-

TABLE II

Characteristics of Sterol Metabolism in Human Hypercholesterolemia

\begin{tabular}{|c|c|c|c|}
\hline Classification & $\begin{array}{c}\text { Sterol } \\
\text { esterification }\end{array}$ & $\begin{array}{l}\text { Sterol ester transfer } \\
\text { to VLDL, LDL }\end{array}$ & $\begin{array}{c}\text { Plasma-cell sterol } \\
\text { transport }\end{array}$ \\
\hline Hyperbetalipoproteinemia & Normal & Reduced & Reversed \\
\hline Dysbetalipoproteinemia & Elevated & Reduced & Reversed \\
\hline Hypertriglyceridemic patients with vascular disease ${ }^{\bullet}$ & Normal & Reduced & Reversed \\
\hline Hypertriglyceridemic patients without vascular disease ${ }^{\bullet}$ & Elevated & Normal & Normal \\
\hline
\end{tabular}

- Documented in terms of the criteria shown in Table I. 
ification and transfer rates (which drive net transport) fall in this in vitro model, due to an accumulation of cholesteryl esters in the medium (3). In vivo, such an accumulation is presumably relieved by clearance of lipoproteins into the liver or other sites. The changes described here do not necessarily define a system at equilibrium, and further research will be required to determine whether, for example, cholesterol efflux rates are modified in response to the increased cell cholesterol levels generated in the incubation period. Nonetheless, the differences in the direction of cholesterol transport induced by plasma from the different metabolic groups clearly reflect differences in the ability of such plasma samples to influence the net movement of cellular cholesterol.

Associated with the abnormality of cholesterol net transport in hyperbetalipoproteinemics, dysbetalipoproteinemics, and hypertriglyceridemics with vascular disease, is a significant inhibition, in each case, of the rate of transfer of cholesteryl esters to VLDL and LDL. As shown previously (3), and as is apparent from the healthy control group in the present study, these lipoproteins normally constitute the major acceptors of cholesteryl esters. This was also found to be the case in the hypertriglyceridemic patients without evident vascular disease. In the case of every patient in this study, an abnormal direction of cholesterol transport was associated with an inhibition of cholesteryl ester transfer to VLDL and LDL, whereas a normal rate of cholesteryl ester transfer was associated with cholesterol net transport between cells and medium of normal direction and magnitude. As shown in Fig. 3, in each case such a reduced rate of cholesteryl ester transfer could be restored to essentially the rates characteristic of normolipidemic plasma by addition of acceptor lipoproteins (VLDL and LDL) from the plasma of individuals supporting normal transfer rates. This finding strongly supports the concept that in the affected patient groups, the inhibition of transfer that was observed was caused not by a defect of the LCATtransfer mechanism per se, but the inability of VLDL and LDL in hyperbetalipoproteinemia, dysbetalipoproteinemia, and hypertriglyceridemia associated with atherosclerotic vascular disease to accept LCAT-derived cholesteryl esters.

It is well established that cells can interiorize plasma lipoproteins as a unit by endocytosis via well-defined receptor sites (34). Only one such system has been defined in fibroblasts, the B-E receptor interiorizing LDL and IDL. Several lines of evidence indicate that this pathway is not the one active in the cholesterol influx described here. Firstly, lipoprotein B-E receptors in cultured cells are normally highly down-regulated when exposed to plasma. Secondly, in cells with a genetic deficiency of the B-E receptor, the rate of influx from plasma was unchanged. Finally, free cholesterol, not esterified cholesterol, was the major lipid interiorized from hyperlipidemic plasma. In the hyperbetalipoproteinemic group there was on average no change in the transport of cholesteryl ester compared with the normal group, whereas free cholesterol transport was at a rate of $-0.5 \mu \mathrm{g} \mathrm{h}^{-1}$. As this represents the difference between influx and an efflux rate of $+0.5 \mu \mathrm{g} \mathrm{h}^{-1}$ under the same conditions, the mean influx rate of free cholesterol was $1.0 \mu \mathrm{g} \mathrm{h}^{-1}$ in this group, relative to an influx of cholesterol as ester of $0.1 \mu \mathrm{g}$ $\mathrm{h}^{-1}$. In the dysbetalipoproteinemic group, calculated mean influx rate of free cholesterol (or efflux-net transport) was $1.5 \mu \mathrm{g} \mathrm{h}^{-1}$ and of ester cholesterol was 0.3 $\mu \mathrm{g} \mathrm{h}^{-1}$, whereas the corresponding values for the hypertriglyceridemic group with abnormal cholesterol transport, calculated in the same manner, were 1.3 and $1.0 \mu \mathrm{g}$, respectively. These proportions do not correspond to the ratio between free and esterified cholesterol in any of the major plasma lipoprotein fractions, yet under the conditions described such transport represented $5-10 \%$ of the free sterol in the medium. Although further evidence is still needed, it appears at this point most likely that the movements of cholesterol from plasma to cells seen in this study represent lipid transfer from one or more plasma lipoprotein complexes, rather than the uptake of intact lipoprotein particles. Lipid transfer has been described from chylomicrons to endothelial cells (35) and from LDL to vascular smooth muscle cells and fibroblasts (36). It is noteworthy that in each case such uptake was seen only in lipoproteins with increased cholesterol content and that uptake was via binding sites that had the kinetic properties of cell surface receptors. Similar mechanisms have been reported for HDL (37).

Although the nature of the lipoprotein particle involved in the accelerated influx that is responsible for abnormal cholesterol transport is not at this point known, two major potential donors can be identified. Firstly, the data on cholesteryl ester transfer indicate that the VLDL and LDL populations in the abnormal plasma samples are poor acceptors for LCAT-derived cholesteryl ester. This may indicate an inhibition of transfer mediated by the cholesteryl ester content of these acceptors. All but two of the donors whose plasma supported abnormal cholesterol transport had a beta or slow pre-beta component of VLDL, which have been shown to represent cholesterol-enriched populations of VLDL (28). However, there was no obvious difference in composition that differentiated the plasma of those hypertriglyceridemics whose plasma supported abnormal net cholesterol transport from those that did not. Secondly, an inhibition of cholesteryl ester transfer was associated with little if any decrease in the rate of ester synthesis. Indeed, in the case of the 
dysbetalipoproteinemic group this rate was increased significantly above the normal rate. This finding indicates that in the plasma of those subjects with abnormal cholesterol transport, cholesteryl ester is being transferred at high rates to the HDL fraction of the plasma. It is therefore also possible that it is through an abnormal HDL particle that the abnormal cholesterol transport is mediated. Further research is needed to distinguish these alternatives.

Our results demonstrate abnormal cholesterol transport between fibroblasts and plasma from patients with two genetic disorders associated with premature atherosclerotic disease, familial hypercholesterolemia, and familial dysbetalipoproteinemia. In addition, the same abnormality is present in some, but not all, patients with elevated VLDL levels and hypertriglyceridemia. Although patients with premature coronary heart disease are often found to be hypertriglyceridemic, several epidemiological studies have failed to show an independent association between plasma triglyceride levels and the incidence of coronary heart disease (38). It is therefore of considerable interest that our hypertriglyceridemic patients who had abnormal cholesterol transport between cells and plasma all had documented atherosclerotic disease, whereas those with normal cholesterol transport did not. These preliminary observations are consistent with the hypothesis that the abnormality of cholesterol transport that we have demonstrated bears a causal relationship to atherogenesis in persons with various forms of hyperlipidemia. Whether a causal relationship exists or not, the cholesterol balance procedures described here may be of value in distinguishing among hypertriglyceridemic persons with and without clinically significant atherosclerotic disease.

Taken together, the results of this study support the concept that several groups at risk for atherosclerotic vascular disease, with diverse changes in concentration and composition of major lipoprotein fractions, share a common defect of plasma cholesterol metabolism. This defect involves an impedance of cholesteryl ester transfer to VLDL and LDL and the uptake of plasma cholesterol into cultured cells by a receptor-independent pathway.

\section{ACKNOWLEDGMENTS}

The expert technical assistance of K. Moser, E. Hoye, J. P. Renston, R. Peters, and B. Fung is acknowledged.

This research was supported by grants from the National Institutes of Health (Arteriosclerosis Specialized Center of Research HL 14237 and HL 23738).

\section{REFERENCES}

1. Fielding, C. J., and P. E. Fielding. 1981. Evidence for a lipoprotein carrier in human plasma catalysing sterol efflux from cultured fibroblasts and its relationship to lecithin:cholesterol acyltransferase. Proc. Natl. Acad. Sci. USA. 78: 3911-3914.

2. Fielding P. E., and C. J. Fielding. 1980. A cholesteryl ester transfer complex in human plasma. Proc. Natl. Acad. Sci. USA. 77: 3327-3330.

3. Fielding, C. J., and P. E. Fielding. 1981. Regulation of human plasma lecithin:cholesterol acyltransferase activity by lipoprotein acceptor cholesteryl ester content. $J$. Biol. Chem. 256: 2102-2104.

4. Slack, J., and G. L. Mills. 1970. Anomalous low density lipoproteins in familial hypercholesterolemia. Clin. Chim. Acta. 29: 15-25.

5. Witztum, J. L., G. Schonfeld, S. W. Weidman, W. E. Giese, and M. A. Dillingham. 1979. Bile sequestrant therapy alters the composition of low-density and high-density lipoproteins. Metab. Clin. Exp. 28: 221-229.

6. Havel, R. J., and J. P. Kane. 1973. Primary dysbetalipoproteinemia. Predominance of a specific apoprotein species in triglyceride-rich lipoproteins. Proc. Natl. Acad. Sci. USA. 70: 2015-2019.

7. Utermann, G., M. Jaeschke, and J. Menzel. 1975. Familial hyperlipoproteinemia Type III: deficiency of a specific apolipoprotein (apo E-III) in the very low density lipoproteins. FEBS (Fed. Eur. Biochem. Soc.) Lett. 56: $352-355$

8. Wilson, D. E., and R. S. Lees. 1972. Metabolic relationships among the plasma lipoproteins. Reciprocal changes in the concentrations of very low and low density lipoproteins in man. J. Clin. Invest. 51: 1051-1057.

9. Rao, S. N., P. J. Magill, N. E. Miller, and B. Lewis. 1980. Plasma high-density lipoprotein metabolism in subjects with primary hypertriglyceridemia: altered metabolism of apoproteins A-I and A-II. Clin. Sci. (Lond.). 59: 359367.

10. Schonfeld, G., A. Bailey, and R. Steelman. 1979. Plasma apolipoprotein A-I and A-II levels in hyperlipidemia. In High Density Lipoproteins. F. T. Lindgren, A. V. Nichols, and R. M. Krauss, editors. American Oil Chemists, Champaign, IL. 20-28.

11. Lewis B., A. Chait, C. M. Oakley, I. D. P. Wooton, D. M. Krikler, G. Sigurdsson, A. Onitiri, and A. February. 1974. Serum lipoprotein abnormalities in patients with ischemic heart disease: comparison with a control population. Br. Med. J. 3: 489-493.

12. Fielding, C. J., and P. E. Fielding. 1982. Cholesterol transport between cells and body fluids. Med. Clin. N. Am. 66: 363-373.

13. Windler, E., Y.-S. Chao, and R. J. Havel. 1980. Regulation of the hepatic uptake of triglyceride-rich lipoproteins in the rat. Opposing effects of homologous apo $\mathrm{E}$ and individual C-proteins. J. Biol. Chem. 255: 83038307.

14. Sherrill, B. C., T. Innerarity, and R. W. Mahley. 1980. Rapid hepatic clearance of the canine lipoproteins containing only the apo $\mathrm{E}$ apoprotein by a high affinity receptor (identity with the chylomicron transport process). J. Biol. Chem. 255: 1804-1807.

15. Mahley, R. W., D. Y. Hui, T. L. Innerarity, and K. H. Weisgraber. 1981. Two independent lipoprotein receptors on hepatic membranes of dog, swine, and man. APO-B, E and APO-E receptors. J. Clin. Invest. 68: 1197-1207.

16. Glomset, J. A., and K. R. Norum. 1973. The metabolic role of lecithin: cholesterol acyltransferase: perspectives from pathology. Adv. Lipid Res. 11: 1-65. 
17. Kannel, W. B., W. P. Castelli, and T. Gordon. 1971. Serum cholesterol, lipoproteins and the risk of coronary heart disease: the Framingham study. Ann. Intern. Med. 74: 1-12.

18. Castelli, W. P., J. T. Doyle, and T. Gordon. 1977. HDL cholesterol and other lipids in coronary heart diseasecooperative lipid phenotyping study. Circulation. 55: 767-772.

19. Heider, J. G., and R. L. Boyett. 1978. The picomole determination of free and total cholesterol in cells in culture. J. Lipid Res. 19: 514-518.

20. Stokke, K. T., and K. R. Norum. 1972. Determination of lecithin: cholesterol acyltransferase in human blood plasma. Scand. J. Clin. Lab. Invest. 27: 21-27.

21. Burstein, M., H. R. Scholnick, and R. Morfin. 1970. Rapid method for the isolation of lipoproteins from human serum by precipitation with polyanions. J. Lipid Res. 11: 583-595.

22. Lowry, O. H., N. J. Rosebrough, A. L. Farr, and R. J. Randall. 1951. Protein determination with the Folin phenol reagent. J. Biol. Chem. 193: 265-275.

23. Fielding, C. J. 1978. Metabolism of cholesterol-rich chylomicrons. Mechanism of binding and uptake of cholesteryl esters by the vascular bed of the perfused rat heart. J. Clin. Invest. 62: 141-151.

24. Havel, R. J., H. A. Eder, and J. H. Bragdon. 1955. The distribution and chemical composition of ultracentrifugally separated lipoproteins in human serum. J. Clin. Invest. 34: 1345-1353.

25. Rush, R., L. Leon, and J. Turrell. 1970. Automated simultaneous cholesterol and triglyceride determinations on the Autoanalyzer II instrument. Advances in Automated Analysis-Technicon International Congress. 1: 503-507.

26. Stewart, C. P., and E. B. Hendry. 1935. The phospholipids of blood. Biochem. J. 29: 1683-1689.

27. Noble, R. P. 1968. Electrophoretic separation of plasma lipoproteins in agarose gels. J. Lipid Res. 9: 693-700.

28. Pagnan, A., R. J. Havel, J. P. Kane, and L. Kotite. 1977. Characterization of human very low density lipoproteins containing two electrophoretic populations: double pre- betalipoproteinemia and primary dysbetalipoproteinemia. J. Lipid Res. 18: 613-622.

29. Havel, R. J., L. Kotite, J.-L. Vigne, J. P. Kane, P. Tun, N. Phillips, and G. C. Chen. 1980. Radioimmunoassay of human arginine-rich apolipoprotein, apoprotein $E$. $J$. Clin. Invest. 66: 1351-1362.

30. Kane, J. P., M. J. Malloy, P. Tun, N. R. Phillips, D. R. Freedman, M. L. Williams, J. S. Rowe, and R. J. Havel. 1981. Normalization of low-density-lipoprotein levels in heterozygous familial hypercholesterolemia with a combined drug regimen. $N$. Engl. J. Med. 304: 251-258.

31. Marcel, Y. L., and C. Vezina. 1973. A method for the determination of the initial rate of reaction of lecithin:cholesterol acyltransferase in human plasma. Biochim. Biophys. Acta. 306: 497-504.

32. Albers, J. J., M. C. Cheung, S. L. Evers, and J. H. Tollefson. 1981. Characterization and immunoassay of apolipoprotein D. Atherosclerosis. 39: 395-409.

33. Ihm, J., J. A. K. Harmony, J. Ellsworth, and R. L. Jackson. 1980. Simultaneous transfer of cholesteryl ester and phospholipid by proteins isolated from human lipoprotein-free plasma. Biochem. Biophys. Res. Commun. 93: 1114-1120.

34. Goldstein, J. L., and M. S. Brown. 1977. The low-density lipoprotein pathway and its relation to atherosclerosis. Annu. Rev. Biochem. 46: 897-930.

35. Fielding, C. J., I. Vlodavsky, P. E. Fielding, and D. Gospodarowicz. 1979. Characterization of chylomicron binding and lipid uptake by endothelial cells in culture. J. Biol. Chem. 254: 8861-8868.

36. St. Clair, R. W., J. J. Mitschelen, and M. Leight. 1980. Metabolism by cells in culture of low density lipoproteins of abnormal composition from non-human primates with diet-induced hypercholesterolemia. Biochim. Biophys. Acta. 618: 63-79.

37. Gwynne, J. T., and B. Hess. 1980. The role of high density lipoproteins in rat adrenal cholesterol metabolism and steroidogenesis. J. Biol. Chem. 255: 10875-10883.

38. Lippel, K., H. Tyroler, H. Eder, A. Gotto, and G. Vahouny. 1981. Relationship of hypertriglyceridemia to atherosclerosis. Arteriosclerosis. 1: 406-417. 